\title{
Production of DNA polymerase from Thermus aquaticus in recombinant Escherichia coli
}

\author{
Sung-Gun Kim ${ }^{1}$, Jong-Tae Park ${ }^{2}$ * \\ ${ }^{1}$ Department of Biomedical Science, Youngdong University, Chungbuk 370-701, Korea \\ ${ }^{2}$ Department of Food Science and Technology, Chungnam National University, Daejeon 305-764, Korea
}

Received on 30 May 2014, revised on 8 August 2014, accepted on 14 August 2014

\begin{abstract}
Among dozens of DNA polymerases cloned from thermophilic bacteria, Taq DNA polymerase from Thermus aquaticus has been most frequently used in polymerase chain reaction (PCR) that is being applied to gene cloning, DNA sequencing, gene expression analysis, and detection of infectious and genetic diseases. Since native Taq DNA polymerase is expressed at low level in T. aquaticus, recombinant Escherichia coli system was used to produce Taq DNA polymerase in a large amount. Taq DNA polymerase was expressed as a soluble form under the control of tac promoter in E. coli, and purified by heat treatment and ion exchange chromatographies. The purified Taq DNA polymerase was nearly homogeneous and exhibited a similar DNA amplification activity with a commercial Taq DNA polymerase.
\end{abstract}

Key words : Taq DNA polymerase, polymerase chain reaction, recombinant protein, Escherichia coli

\section{Introduction}

Since polymerase chain reaction (PCR) is a useful method for the rapid amplification of target DNA sequences (Erlich, 1989), it has been extensively used in the biotechnology field including disease diagnosis, gene cloning and DNA sequencing (Bachmann et al., 1990; Hamilton et al., 2001; Louws et al., 1999; Marchuk et al., 1991). The gene amplification process involves repeated cycles of heat denaturation of a DNA template, annealing of primers to the complementary DNA strands, and extension of the annealed primers with DNA polymerase and deoxynucleotides, which results in the exponential amplification of the DNA sequence between the flanking primers. Because of the heat denaturation step, a DNA polymerase that is stable during the repetitive thermal denaturation is required in PCR reactions.

More than 50 thermostable DNA polymerases have been isolated from various organisms including

\footnotetext{
*Comesponding author: Tel: +82-42-821-6728

E-mail address: jtpark@cnu.ac.kr
}

thermophiles and archaea. The thermostable DNA polymerases elevated optimal temperature for polymerization of 70 to $80 \mathrm{C}$ and are single-subunit proteins of 80 to $115 \mathrm{kDa}$ in solution, which are different to multi-subunit DNA polymerases from eubacteria (Klimczak et al., 1985; Kong et al., 1993; Takagi et al., 1997). Due to their potential industrial applications, various thermostable DNA polymerases have been studied for the structure and thermostability relationship and commercialized in many biotechnology companies. Among them, Taq DNA polymerase has been most commonly used in PCR. It was first purified in 1976 from Thermus aquaticus that was isolated from a hot spring in Yellowstone National Park (Chien et al., 1976). The PCR technique using Taq DNA polymerase was patented by Cetus Corporation in 1989 and currently the market for Taq DNA polymerase is in the hundreds of millions of dollar per year. However, since most thermostable enzymes are present at very low level in the thermophilic bacteria which are difficult to grow to obtain large quantity protein, the purification of Taq DNA polymerase from $T$. aquaticus 
results in low yields.

In this study, recombinant $E$. coli was exploited to produce Taq DNA polymerase in a large amount. Taq DNA polymerase was produced in recombinant $E$. coli where an expression plasmid cloned with polA coding sequence under the control of tac promoter was transformed. Taq DNA polymerase expressed as a soluble form in $E$. coli was purified via a heat treatment and a series of chromatography steps, and then applied to PCR reactions.

\section{Materials and Methods}

\section{Bacterial strain and plasmid}

A plasmid p33 was used for the expression of Taq DNA polymerase. The expression plasmid p33 was kindly provided by Dr. Masayori Inouye at University of Medicine and Dentistry of New Jersey. The expression of Taq DNA polymerase is under the control of the tac promoter, which can be induced by adding isopropyl$\beta$-d-thiogalactopyranoside (IPTG). E. coli DH5a was used for the expression of Taq DNA polymerase.

\section{Culture condition}

Recombinant $E$. coli DH5a cells harboring plasmid p33 were cultured at $37^{\circ} \mathrm{C}$ in a $500-\mathrm{mL}$ baffled flask containing Luria-Bertani medium (10 g/L tryptone, 5 $\mathrm{g} / \mathrm{L}$ yeast extract, $10 \mathrm{~g} / \mathrm{L} \mathrm{NaCl}$ ) supplemented with 50 mg/L ampicillin. Expression of Taq DNA polymerase was induced at the logarithmic growth phase (OD600 $=0.5 \sim 1.0$ ) by adding $1 \mathrm{mM}$ isopropyl- $\beta-\mathrm{d}$-thiogalactopyranoside (IPTG), and allowed to grow for another $4 \mathrm{hr}$.

\section{Purification of Taq DNA polymerase}

The cells induced with IPTG for $4 \mathrm{hr}$ were collected at 6,000 rpm for $10 \mathrm{~min}$, and resuspended in $50 \mathrm{ml}$ of a resuspension buffer (50 mM Tris, pH 7.9, $50 \mathrm{mM}$ glucose, $1 \mathrm{mM}$ EDTA). The resuspended cells were disrupted by sonication, and the insoluble debris was removed by centrifugation at $12,000 \mathrm{rpm}$ for $20 \mathrm{~min}$ at $4^{\circ} \mathrm{C}$. The supernatant was incubated at $75^{\circ} \mathrm{C}$ for 1 hr to denature $E$. coli cellular proteins, which were removed by centrifugation at 12,000 rpm for $20 \mathrm{~min}$ at $4^{\circ} \mathrm{C}$. The supernatant was applied to a DEAE column equilibrated with an anion binding buffer (10 mM Tris, pH 7.9, 1 mM EDTA, 0.5\% Tween 20). After washing 5 column volumes, proteins bound to the anion exchanger were eluted by increasing $\mathrm{KCl}$ concentration up to $500 \mathrm{mM}$. The fractions containing Taq DNA polymerase was pooled and then desalted by dialysis against a cation binding buffer (20 mM HEPES, pH 6.9, 1 mM EDTA, 0.5\% Tween 20) using a $10 \mathrm{kDa}$ MWCO dialysis membrane for a subsequent purification step. The Taq DNA polymerase purified partially in the anion exchange chromatography was subjected to cation exchange chromatography on SP Sepharose Fast Flow using a $10 \mathrm{ml}-$ Econo pack column (Bio-rad, Herculis, CA, USA). Taq DNA polymerase bound to the cation exchanger was eluted with $\mathrm{KCl}$ in a stepwise gradient of $0.0-500 \mathrm{mM}$ over 10 column volumes. The purified Taq DNA polymerase was stored at $-20^{\circ} \mathrm{C}$ in a Taq storage buffer (50 mM Tris, pH 8.0, $100 \mathrm{mM}$ $\mathrm{NaCl}, 0.1 \mathrm{mM}$ EDTA, $5.0 \mathrm{mM}$ DTT, 1.0\% Triton $\mathrm{X}-100$, $50 \%$ glycerol).

\section{Polymerase chain reaction}

The relative Taq DNA polymerase activities were determined by comparing band intensities of DNA amplified by polymerase chain reaction (PCR) using the purified and the commercial (Solgent Co., Daejeon, Korea) Taq DNA polymerases. In this study, a $10 \mathrm{X}$ reaction buffer (100 mM Tris, $\mathrm{pH} 9.0,500 \mathrm{mM} \mathrm{KCl}$, 1.0\% Triton $\mathrm{X}-100,20 \mathrm{mM} \mathrm{MgCl} 2,10 \mathrm{mM} \mathrm{b}$-mercaptoethanol) was also prepared for PCR. E. coli BL21 (DE3) genomic DNA was used as the template DNA to 
Table 1. Oligonucleotides used in this study.

\begin{tabular}{ll}
\hline Oligonucleotide & Nucleotide sequence \\
\hline ppiA-F & 5'-GAATTCCTCGAGCATGTTCAAATCGACCCTGGCGGCGATG-3' \\
ppiA-R & 5'-AATCGCGAGCTCTTATTACGGCAGGACTTTAGCGGAAAGGAT-3' \\
\hline
\end{tabular}

amplify the coding sequence of ppiA gene. The primers used to amplify ppiA gene in the PCR reaction are listed in Table 1. The PCR reaction was carried out in a $50 \mu \mathrm{l}$ mixture containing $1 \mu \mathrm{l}$ of plasmid DNA (20 ng), $5.0 \mu \mathrm{l}$ of the $10 \mathrm{X}$ reaction buffer, $2.5 \mu \mathrm{l}$ of a deoxynucleosides triphosphate (dNTP) mixture (2.5 $\mathrm{mM}$ of each dNTP), $2 \mu \mathrm{l}$ of each primer (10 pM), 38 $\mu \mathrm{l}$ of DNase-free water and $1 \mu \mathrm{l}$ of the purified or the commercial Taq DNA polymerase. After amplification with an automated thermocycler (GeneAmp PCR 2400, Perkin Elmer, Norwalk, CT, USA) for 30 cycles (30 sec at $94^{\circ} \mathrm{C}$ for denaturation, $30 \mathrm{sec}$ at $55^{\circ} \mathrm{C}$ for annealing and $1 \mathrm{~min}$ at $72^{\circ} \mathrm{C}$ for extension), $10 \mu \mathrm{l}$ of PCR mixture was analyzed by electrophoresis on a $1 \%$ agarose gel in 0.5X TAE buffer.

\section{Analytical methods}

Optical density of the cells was measured at $600 \mathrm{~nm}$ of wavelength using a spectrophotometer (Optizen POP, Optizen, Daejeon, Korea). Dry cell weight was then obtained using a pre-determined correlation factor (0.367) between optical density and dry cell weight. Protein concentration was determined using the protein assay kit (Bio-rad) according to the manufacturer's instruction. The protein samples were analyzed by SDS-PAGE using 14\% gel with the MiniPROTEIN囚 3 Electrophoresis Cell (Bio-rad). Proteins on the gel were visualized by staining with Coomassie brilliant blue R-250 (Sigma, Saint Louis, MO, USA).

\section{Results and Discussion}

\section{Expression of Taq DNA polymerase}

To assess the expression of Taq DNA polymerase in

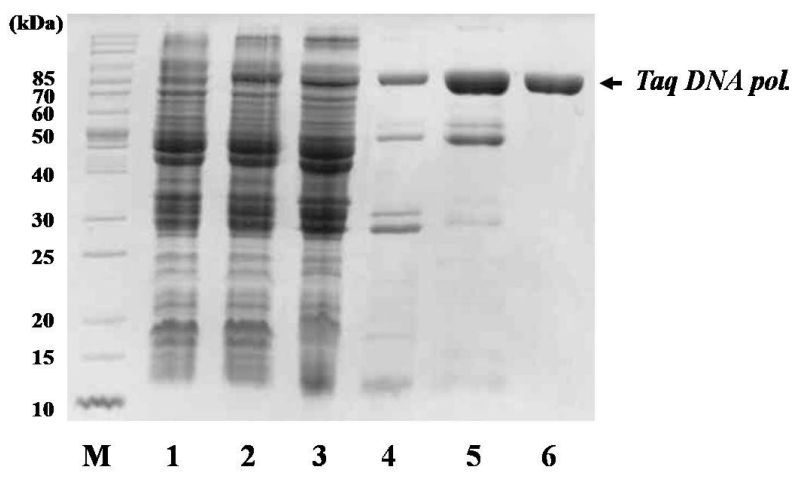

Fig. 1. SDS-PAGE analysis for expression and purification of Taq DNA polymerase from recombinant E. coli. Lane M, Marker proteins; Lane 1, E. coli cells before induction; Lane 2, E. coli cells after induction with IPTG; Lane 3, Soluble fraction after cell disruption; Lane 4, Soluble fraction after heat treatment at $75 \mathrm{C}$ for $1 \mathrm{hr}$; Lane 5, Anion exchange chromatography; Lane 6 , Cation exchange chromatography.

recombinant $E$. coli, the plasmid p33 was transformed into $E$. coli $\mathrm{DH} 5 \mathrm{a}$. When the recombinant $E$. coli strain harboring p33 was induced with $1 \mathrm{mM}$ IPTG in a batch culture containing LB medium, the expression of Taq DNA polymerase was analyzed with SDS-PAGE (Fig. 1). In comparison with the cells before induction, a distinct band of ca. $90 \mathrm{kDa}$ was visualized in the cells after IPTG induction. The apparent molecular weight of Taq DNA polymerase is in accordance with its theoretical molecular weight of $93.9 \mathrm{kDa}$, suggesting that the full-length Taq DNA polymerase is able to be produced in recombinant $E$. coli. Even though Taq DNA polymerase was not overexpressed in $E$. coli, but it was determined as a soluble form. The low expression level of Taq DNA polymerase is likely attributed to the high frequency of rare codons of $E$. coli in the gene of Taq DNA polymerase. The rare codons in the gene of Taq DNA polymerase was analyzed. These amino acid residues include arginine, leucine, proline, which are present in overall region of the gene (data not shown). 


\section{Purification of Taq DNA polymerase}

Since the Taq DNA polymerase expressed in E. coli is a soluble form and has a thermostable nature, the cell lysate was incubated at $75 \mathrm{C}$ for $1 \mathrm{hr}$ prior to chromatographic purification steps. The Taq DNA polymerase was not observed in the insoluble fraction, indicating that it did not undergo the heat-denatured aggregation (data not shown). The vast majority of $E$. coli cellular proteins were denatured and thus eliminated by centrifugation following the heat treatment (Fig. 1, lane 4). There were still various contaminant proteins after the heat treatment even at $75 \mathrm{C}$ for $1 \mathrm{hr}$, that are likely thermostable $E$. coli proteins. Fifteen cellular proteins of $E$. coli (DnaK, transcription pausing factor L (NusA), trigger factor $(\mathrm{TF})$, maltose-binding proteins (MBP), galactose glucosebinding protein, FK-506-binding protein (FKBP), $\mathrm{D}$-ribose binding protein ( $\mathrm{RbsB})$, adenylate kinase $(\mathrm{AKN})$, outer membrane lipoprotein carrier protein, ribosomal protein S19 (RS19), putative EscN protein (EscN), and GroES) were identified to be thermostable (Thapa et al., 2008). For further purification, the soluble fraction of the heat-treated cell lysate was subjected to an anion exchange chromatography with Tris buffer at pH 7.9, since its theoretical isoelectric point (pI) is 6.03. The proteins electrostatically bound to a anion exchanger $Q$ Sepharose fast flow resin was eluted by increasing $\mathrm{KCl}$ concentration in a stepwise manner. The SDS-PAGE analysis for the eluted fractions showed that major contaminant $E$. coli proteins were observed in the flow-through fractions but several contaminant proteins were co-purified with Taq DNA polymerase in the anion exchange chromatography. Taq DNA polymerase was eluted at $0.1 \mathrm{M} \mathrm{KCl}$. The fractions containing Taq DNA polymerase were pooled and desalted for a subsequent purification step. The desalted sample was loaded to a column packed with a cation exchanger (SP Sepharose fast flow). The column was washed with HEPES buffer ( $\mathrm{pH}$ 6.9) and then eluted with a stepwise gradient of $\mathrm{KCl}$. The co-purified proteins in the anion exchange chromatography did not bind to the cation exchanger. However, most Taq DNA polymerase was eluted upon increasing $\mathrm{KCl}$ concentration, indicating an electrostatic binding of Taq DNA polymerase to the cation exchanger. The purity of Taq DNA polymerase in the cation exchange chromatography was nearly homogenous based on SDS-PAGE and densitometric analyses. The purified Taq DNA polymerase in the cation exchange chromatography was stored at $-20^{\circ} \mathrm{C}$ after a bufferexchange to a storage buffer.

\section{Activity of Taq DNA polymerase}

The purified Taq DNA polymerase was compared with a commercial Taq DNA polymerase in terms of apparent molecular weight and purity. Figure 2 clearly shows that the purified Taq DNA polymerase has the same molecular weight as the commercial Taq DNA polymerase. In addition, both the purified and the commercial Taq DNA polymerase were shown as a single band in the SDS-PAGE gel. The band intensity

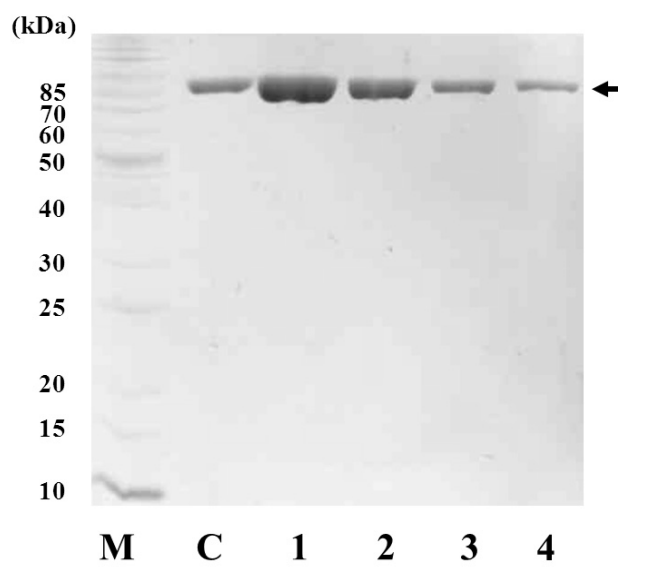

Fig. 2. Analysis of apparent molecular weight for purified and commercial Taq DNA polymerases. The position of Taq DNA polymerase was indicated by the arrow. Lane M, Marker proteins; Lane C, commercial Taq DNA polymerase (Solgent Co.) (1X); Lane 1, purified Taq DNA polymerase (1X); Lane 2, purified Taq DNA polymerase (0.5X); Lane 3, purified Taq DNA polymerase $(0.25 \mathrm{X})$; Lane 4 , purified Taq DNA polymerase (0.125X). 


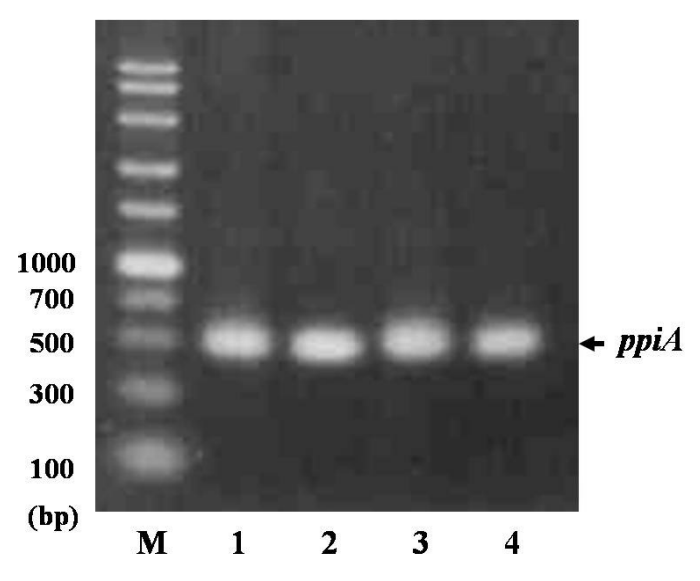

Fig. 3. Amplifications of ppiA gene of E. coli using the PCR kit produced in this study and a commercial kit. Lane M, DNA ladder; Lane 1, the purified Taq DNA polymerase and the reaction buffer prepared in this study; Lane 2, the commercial Taq DNA polymerase and the reaction buffer prepared in this study; Lane 3, the purified Taq DNA polymerase and the commercial reaction buffer ; Lane 4, the commercial Taq DNA polymerase and the commercial reaction buffer.

of the commercial Taq DNA polymerase was similar with that of the 4-fold diluted purified Taq DNA polymerase. Considering that the enzymatic activity of the commercial available Taq DNA polymerase is $5 \mathrm{U} / \mu \mathrm{l}$, the activity of the purified Taq DNA polymerase could be estimated to be about $20 \mathrm{U} / \mu \mathrm{l}$. The activity of the purified polymerase was also evaluated by PCR amplification and compared to the commercial Taq DNA polymerase. In the PCR reactions, both the Taq DNA polymerases effectively amplified ppiA gene of $573 \mathrm{bp}$ from genomic DNA of $E$. coli BL21(DE3) showing the same band intensity (Fig. 3). When a PCR reaction buffer prepared in this study was replaced with the reaction buffer supplied with the commercial Taq DNA polymerase, the ppiA gene was amplified at the same levels as shown in Fig. 3. This result clearly demonstrates that the Taq DNA polymerase produced in this study has a similar efficiency to the commercial Taq

DNA polymerase.

\section{References}

Bachmann B, Lüke W, Hunsmann G. 1990. Improvement of PCR amplified DNA sequencing with the aid of detergents. Nucleic Acids Research 18:1309.

Chien A, Edgar DB, Trela JM. 1976. Deoxyribonucleic acid polymerase from the extreme thermophile Thermus aquaticus. Journal of Bacteriology 127:1550-1557.

Erlich HA. 1989. Polymerase chain reaction. Journal of Clinical Immunology 9:437-447.

Hamilton SC, Farchaus JW, Davis MC. 2001. DNA polymerases as engines for biotechnology. BioTechniques 31:370-383.

Klimczak L, Grummt F, Burger KJ. 1985. Purification and characterization of DNA polymerase from the archaebacterium Sulfolobus acidocaldarius. Nucleic Acids Research 13:52695282.

Kong H, Kucera R, Jack W. 1993. Characterization of a DNA polymerase from the hyperthermophile archaea Thermococcus litoralis. Vent DNA polymerase, steady state kinetics, thermal stability, processivity, strand displacement, and exonuclease activities. Journal of Biological Chemistry 268:1965-1975.

Louws F, Rademaker J, De Bruijn F. 1999. The three Ds of PCR-based genomic analysis of phytobacteria: diversity, detection, and disease diagnosis. Annual Review of Phytopathology 37:81-125.

Marchuk D, Drumm M, Saulino A, Collins FS. 1991. Construction of T-vectors, a rapid and general system for direct cloning of unmodified PCR products. Nucleic Acids Research 19: 1154-1154.

Takagi M, Nishioka M, Kakihara H, Kitabayashi M, Inoue H, Kawakami B, Oka M, Imanaka T. 1997. Characterization of DNA polymerase from Pyrococcus sp. strain KOD1 and its application to PCR. Applied and Environmental Microbiology 63:4504-4510.

Thapa A, Shahnawaz M, Karki P, Dahal GR, Sharoar MG, Shin SY, Lee JS, Cho B, Park I-S. 2008. Purification of inclusion body-forming peptides and proteins in soluble form by fusion to Escherichia coli thermostable proteins. BioTechniques 44:787-798. 